\title{
THE PORTUGUESE VERSION OF THE PERSONAL HEALTH SCALE: A VALIDATION STUDY IN SOUTHERN BRAZIL
}

\author{
Carlos Zubaran ${ }^{1,2}$, Karina Persch ${ }^{2}$, Desire Tarso ${ }^{2}$, Ana Elisa Ioppi² , Juan Mezzich
}

\begin{abstract}
Zubaran C, Persch K, Tarso D, Ioppi AE, Mezzich J. The portuguese version of the personal health scale: a validation
\end{abstract} study in southern Brazil. CLINICS. 2007; 62(4):419-26.

The Personal Health Scale is a concise instrument for comprehensive culture-informed and self-rated assessment of general health status and well-being. It is composed of 10 questions that appraise different health dimensions collated from the international literature, including aspects ranging from somatic and psychological domains to social functioning and insight.

PURPOSE: In this investigation, results of a study conducted in Southern Brazil to test and validate the Portuguese version of the Personal Health Scale (PHS-Pt) are presented.

METHOD: This study analyzes data from a sample of 120 Brazilian volunteers ( 90 patients and 30 health care professionals). All patients completed the Portuguese version of the Personal Health Scale under a minimal guidance by trained examiners, who followed standardized instructional procedures.

RESULTS: The internal consistency of the PHS-Pt attained a Cronbach's a of 0.75 among patients and of 0.69 among health care professionals. The test-retest reliability correlation coefficient yielded a score of 0.82 . Furthermore, the PHS-Pt was able to detect a significant discriminating validity between the 2 evaluated samples $(P<.001)$.

CONCLUSIONS: The original English version of the Personal Health Scale was successfully adapted to Portuguese as methodologically demonstrated herein. The PHS-Pt constitutes a reliable and trustworthy research instrument for evaluating health status in Brazil, since it is appropriately designed to distinguish different groups of volunteers regarding their health status.

KEYWORDS: Health status. Validation studies. Questionnaires. Scales. Brazil.

\section{INTRODUCTION}

During the latter part of the $20^{\text {th }}$ century, there was a heightened appreciation of the subjective expressions of patients. ${ }^{1}$ The field of health status and quality of life measurement has been evolving as a formal discipline with structured theoretical foundations and specific methodology for more than 30 years. $^{2}$ The concepts of health status, wellbeing, and quality of life started to be conceived as researchable topics in the mid-1970s, when these constructs were

1.Whangarei Hospital - Psychiatry - New Zealand

2. University of Caxias do Sul - Biomedical Sciences- Rio Grande do Sul, Brazil

3. Mount Sinai School of Medicine, New York, USA

Received for publication on February 05, 2007

Accepted for publication on April 04, 2007 often encompassed among psychosocial correlates of wellbeing and physiological factors. ${ }^{3,4}$ In the late 1980 s, some authors adopted health screening procedures for examining the limitations imposed by the disease process on patients' well-being and social functioning. ${ }^{5-8}$ It was then understood that general health status is amenable to assessment and measurement, and henceforth, clinicians and researchers started to develop psychometric tools to evaluate the impressions of a given patient about his own health condition. The concept of personal health relates to the perception each individual has of his own health status.

Although the concept of health has been subject to cultural and historical adjustment, according to the World Health Organization, health can be defined as a state of complete physical, mental, and social well-being. ${ }^{9-11}$ Yet, 
there is a current tendency to reexamine the conceptual boundaries of health in order to include additional elements such as socio-cultural conditions as well as factors contributing to mental and physical health, which ideally would transcend the rather circumscribed dichotomy of the healthdisease process. ${ }^{12}$ It is currently acknowledged that efforts to investigate and evaluate quality of life, social functioning, health status, and well-being are valid enterprises within clinical and research contexts. ${ }^{13}$

Clinicians and policymakers now agree on the importance of measuring both general and health-related quality of life. ${ }^{14}$ The growing interest in assessing health status in the general population has spurred a demand for specific questionnaires to measure this construct within a reliable and valid framework. Among other applications, it has been demonstrated that general health questionnaires are useful tools for identifying episodes of emotional distress in general practice consultations. ${ }^{15}$ Health questionnaires are divided into 2 distinct domains of analysis, which are related to generic or disease-specific health measures. ${ }^{16}$ General health instruments inquire about health in a broad sense, whereas disease-specific questionnaires assess narrower aspects of life related to a specific problem, function, or manifestation of an underlying disease process. ${ }^{17}$

Health status questionnaires provide parameters for monitoring the impact of disease activity as well as the effect of therapeutic interventions. Health assessment tools may also provide important information about the need for medical assistance as well as the degree of disability of a given patient. Various generic health scales and questionnaires have been developed and adapted to an array of languages and cultures, including the Short Form 36-item Health Survey (SF-36), the Nottingham Health Profile (NHP), the Stanford Health Assessment Questionnaire (HAQ), the Modified Health Assessment Questionnaire (MHAQ), the EuroQol (EQ), and the Short Form 12-item Health Survey Questionnaire (SF-12). ${ }^{18-23}$

Due to the increment in the number of multinational and multicultural research projects, there has been a proportional increase in the number of studies designed to test and adapt a series of health status instruments to different countries and languages. ${ }^{24-26}$ Most of the questionnaires were originally developed in English-speaking countries. Presently, several health status instruments are available in different languages, and some have been tested and validated in numerous countries. ${ }^{27}$ Nevertheless, the methodological details of translation and adaptation of questionnaires originally developed in English for future use in other countries have received surprisingly little attention. ${ }^{28}$ It is now a consensus that, when tested across different cultures, measures must not only be well translated linguistically, but also be well adapted culturally in order to guarantee the content validity of the instrument. ${ }^{24,29-31}$

The Personal Health Scale (PHS) is a unidimensional questionnaire designed to measure the construct of personal health status from a user perspective. It contains 10 items that were obtained through a critical review of the international literature. The Personal Health Scale is an ordinal scale that measures the frequency of 10 dimensions and rates each one numerically from 0 to 3 . The score magnitude of each domain parallels the frequency of each correlated dysfunction or symptom, so that the higher the overall score of the instrument, the lower the personal health status.

In the development of the PHS, particular attention has been paid to multicultural issues, so that specific conditions presented by immigration groups are surveyed in the instrument. ${ }^{30}$ Different versions of the PHS have been already validated in an array of languages. ${ }^{32-34}$ In this investigation, results of a study conducted in Brazil to test and validate the Portuguese version of the Personal Health Scale (PHS$\mathrm{Pt}$ ) are presented.

The main objective of this report was to present details of the application of the PHS-Pt in a sample of Brazilian volunteers in the city of Caxias do Sul, Southern Brazil. Furthermore, the aim of this study was to evaluate empirically the feasibility, internal structure consistency, reliability, and discriminant validity of the PHS-Pt in order to establish the validation of this instrument for investigational purposes in Brazil. It is concluded that the PHS-Pt was well understood by research volunteers and was effective for significantly differentiating between 2 discordant samples according to their purported health conditions. Figure 1 shows the PHS-Pt.

\section{METHODS}

\section{Subjects}

The study investigated 2 samples of adult volunteers: one included 90 patients (30 from inpatient psychiatric units, 30 from outpatient facilities, and 30 from general hospital units), and the other comprised 30 health care professionals from the same general hospital. The psychiatric units are located at Paulo Guedes Clinic, which is a 350-bed tertiary care psychiatric hospital. Both the general hospital and the outpatient clinics are located on the main campus of the University of Caxias do Sul. All 3 health care services are also graduate training facilities associated with UCS and located in the city of Caxias do Sul in Southern Brazil.

All patients who volunteered to participate in this investigation were assisted via the Brazilian public health system (SUS). Health care professionals who voluntarily 
participated in this investigation were actively working nurses and nurse assistants who denied having major health problems during a clinical interview prior to their enrollment in the study. All professionals were employed under conventional working conditions and professional agreements at the UCS general hospital. Portuguese was the native language of all volunteers.

\section{INFORMED CONSENT}

This study was endorsed by institutional Ethics and Research Committee of the University of Caxias do Sul. All volunteers signed a consent form to declare a voluntary agreement with all procedures implicated in this project. Taking into account that a substantial fraction of the sample population was illiterate or semi-illiterate, all patients completed the PHS-Pt under minimal guidance by trained examiners, who followed standardized instructional procedures.

\section{Procedures}

The PHS was translated into Portuguese taking into account semantic, idiomatic, experiential, cultural, and conceptual equivalence between the source and the target instruments. ${ }^{31}$ Two investigators proficient in both Portuguese and English developed the final Portuguese version of the PHS. Each investigator conducted the translation and adaptation in one direction, from one language to the other (translation and back-translation). The final adapted version of the instrument was established by a committee of specialists, by taking into comparison both the translation and back-translation of the instrument. This committee consisted of professionals fully cognizant of the subject under investigation. Many of them were versed in both languages. The various drafts of the PHS, in each language, were progressively improved by using relevant information obtained from a series of applications of the questionnaire to various samples of patients and professionals. ${ }^{32-35}$

\section{ANALYSIS}

Evaluation parameters and statistical analysis included the following factors: feasibility (time of completion and ease of use); internal structure (internal consistency and factorial structure); test-retest reliability (an interval of 3-7 days apart), and discriminant validity, as determined by comparing the mean scores of 2 samples with presumably different levels of health status. Analysis of variance (ANOVA) followed by post hoc analysis (Tukey B) were applied exclusively to compare different subgroups separately.

\section{RESULTS}

In the sample of patients, $45 \%$ of the volunteers were men, and ages ranged from 20 to 70 years, with a mean of 47.7 years. In the sample of health professionals, $5 \%$ were men, and ages ranged from 20 to 59 years, with a mean of 37 years. All health professionals were actively working during the investigational period.

\section{Feasibility Results}

The average time that volunteers from the sample of patients took to complete the questionnaire was $3.8 \mathrm{~min}$ utes, while volunteers from the sample of health professionals completed the questionnaire in 2.8 minutes. Table 1 presents the distribution of the variable "ease of use" for the 2 samples, as perceived by volunteers and interviewers. The large majority of patients and their respective interviewers considered the questionnaire as "somewhat easy" or "very easy" to complete. All of the health professionals and their respective interviewers considered PHS-Pt as "somewhat easy" or "very easy" to complete.

Table 1 - Ease of use of the Portuguese version of the Personal Health Scale, according to the perceptions of volunteers and interviewers in groups of patients and health professionals.

\begin{tabular}{lcccc}
\hline & \multicolumn{2}{c}{$\begin{array}{c}\text { As Perceived by } \\
\text { Volunteer }\end{array}$} & \multicolumn{2}{c}{$\begin{array}{c}\text { As Perceived by } \\
\text { Interviewer }\end{array}$} \\
Degrees ofEase of Use & Patients & Professionals & Patients & Professionals \\
\hline Very easy & $51,2 \%$ & $43,3 \%$ & $43,3 \%$ & $86,6 \%$ \\
Somewhat easy & $36,6 \%$ & $56,7 \%$ & $46,6 \%$ & $13,3 \%$ \\
Somewhat difficult & $11,1 \%$ & $0 \%$ & $8,8 \%$ & $0 \%$ \\
Very difficult & $1,1 \%$ & $0 \%$ & $1,1 \%$ & $0 \%$ \\
\hline
\end{tabular}

\section{Internal Structure Results}

The internal consistency of the PHS-Pt (correlation of the items to the total score) attained a Cronbach's a of 0.75 , when administered to the sample of patients, and of 0.69 , when administered to the sample of professionals (out of a maximum of 1.00 in each case). The factor analysis (main components) of the 10 items of the PHS-Pt, on the combined sample of 120 patients and health professionals, yielded 1 factor, which accounts for a substantial $32.66 \%$ of item variance. The results of the factor analysis are represented in Table 2. These results demonstrate adequate homogeneity and coherence of all items included in the scale, which represents an integrated concept of health status. 
Table 2 - Factorial structure of the Portuguese version of the Personal Health Scale in a combined sample of patients and of health professionals.

\begin{tabular}{lc}
\hline Items & Factor \\
\hline 1. Have you had difficulty in falling asleep? & 0,73 \\
2. Have you felt frightened or alarmed? & 0,73 \\
3. Have you felt nervous or tense? & 0,71 \\
4. Have you felt sad? & 0,70 \\
5. Have you had trouble enjoying your daily activities? & 0,73 \\
6. Have you felt tired? & 0,76 \\
7. Have you failed to do or mismanaged your work? & 0,75 \\
8. Have you had difficulty in relating to your family? & 0,74 \\
9. Have you had difficulty in relating to friends and neighbors? & 0,74 \\
10. Have you perceived that you have emotional problems and & \\
that you need professional help? & 0,73 \\
\hline
\end{tabular}

\section{Reliability Results}

The test-retest reliability analysis was conducted for each item separately. Most of items yielded results of 0.80 or higher. The average score of the test-retest reliability analysis, considering the totality of items, yielded a score of 0.82 .

\section{Discriminant Validity Results}

Discriminant validity analysis of the PHS-Pt was conducted for distinct groups of volunteers in the sample. A significant difference between the sample of patients and the sample of health professionals was demonstrated for most of the items in the scale when analyzed separately. A significant difference $(P<.001)$ between the means of the instrument's final scores in the groups of patients (7.38) and health professionals (4.90) was observed, which attests to the substantial discriminant validity of the PHS-Pt.

The means of questions 1, 4, 5 and 9 were not significantly different between patients and health workers. These questions are related to sleep, mood, daily tasks, and interpersonal relationships. Analysis of variance (ANOVA) followed by post hoc analysis (Tukey B) also did not reveal any significant difference between the means when these specific questions were compared among the 4 subgroups.

According to a Relative Operating Characteristic (ROC) analysis, which considers both sensitivity and specificity factors, the best cut-off value was a score of 6 (AUC = 0.686; $\mathrm{SD}=0.51 ; 95 \% \mathrm{CI}=0.585-0.786)$, which accounts a sensitivity of $73.3 \%$ and a specificity of $70 \%$. A ROC curve is obtained by plotting sensitivity against the falsepositive rate for all possible cut-off points of the screening instrument. The curve represents the performance of the instrument in discriminating between 'cases' and 'noncases' across the total spectrum of morbidity, and the area under the ROC curve (AUC) can be used as an index of the discriminating ability of a screening instrument. ${ }^{36}$

Table 3 shows a 2 X 2 table for a variety of values for case/noncase threshold. Sensitivity and specificity figures as well as positive and negative predictive values according to the above-mentioned cut-off score are also presented on Table 3. The limitrophe scores of 5 and 7 were also tested but presented unfavorable outcomes compared to the proposed cut-off of 6 .

Table 3 - Values for cases and non-case of the Portuguese Version of the Personal Health Scale according to the cutoff score of 6.

\begin{tabular}{lccc}
\hline Test & Patients & Controls & Total \\
\hline PHS-Pt e" 6 & 66 & 9 & 75 \\
PHS-Pt $<6$ & 24 & 21 & 45 \\
Total & 90 & 30 &
\end{tabular}

Sensitivity $=0,733$; Acuracy $=0,725$; Positive Preditive Value $=0,888$; Specifity $=0,7 ;$ Negative Preditive Value $=0,466$

\section{DISCUSSION}

The PHS-Pt was well accepted by patients and health professionals alike. The questions were answered with relative ease and rapidity (less than 4 minutes to complete), which demonstrates the ease of use of the instrument. As observed elsewhere, questionnaires that investigate health status and quality of life in multiple domains and with a larger number of questions tend to take longer than the PHS-Pt to be completed. ${ }^{37-38}$

The internal consistency of the PHS-Pt, as indicated by the results of the coefficients of Cronbach, was satisfactory for patients and health professionals alike, which demonstrates that the instrument coherently investigates the construct of health status as measured uniformly by its items. The validation study of the Latino version of the PHS found similar results. The test-retest reliability of PHS-Pt is demonstrated by a substantial correlation $(r=0.82)$ between questionnaires completed from 3 to 7 days after the initial interview. In order to prevent a major influence caused by the natural course of a given disease and/or the symptomatic fluctuation of the clinical state of patients on our results, we aimed at minimal test-retest intervals.

The discriminant validity was demonstrated by a significant difference between the means of the final scores in the 2 different groups. Health workers were actively working during the investigational period and therefore were not subject to any frank disability. Compared to volunteers from the inpatient units (psychiatric and general hospital) and to volunteers from outpatient facilities, health 


\section{ESCALA DE SAÚDE PESSOAL}

Nome:

Código:

Idade:

anos Sexo: Feminino

Masculino

Grupo Populacional:

Entrevistador:

Data:

Instruções: Por favor, circule a freqüência com que você tem experimentado cada um dos seguintes itens durante o mês passado.

\begin{tabular}{|c|c|c|c|}
\hline Itens & Raramente & Às vezes & $\begin{array}{l}\text { Quase } \\
\text { sempre }\end{array}$ \\
\hline 1. Você tem tido dificuldade para pegar no sono? & 0 & 1 & 2 \\
\hline 2. Você tem se sentido assustado ou alarmado? & 0 & 1 & 2 \\
\hline 3. Você tem se sentido nervoso ou tenso? & 0 & 1 & 2 \\
\hline 4. Você tem se sentido triste? & 0 & 1 & 2 \\
\hline $\begin{array}{l}\text { 5. Você tem tido problemas para aproveitar } \\
\text { atividades diárias? }\end{array}$ & 0 & 1 & 2 \\
\hline 6. Você tem se sentido cansado? & 0 & 1 & 2 \\
\hline $\begin{array}{l}\text { 7. Você tem fal tado ao trabalho ou não feito bem seu } \\
\text { trabalho? }\end{array}$ & 0 & 1 & 2 \\
\hline $\begin{array}{l}\text { 8. Você tem tido dificuldade de se relacionar com sua } \\
\text { família? }\end{array}$ & 0 & 1 & 2 \\
\hline $\begin{array}{l}\text { 9. Você tem tido dificuldade de se relacionar com } \\
\text { amigos e vizinhos? }\end{array}$ & 0 & 1 & 2 \\
\hline $\begin{array}{l}\text { 10. Você tem sentido que tem problemas emocionais } \\
\text { e precisa de ajuda profissional? }\end{array}$ & 0 & 1 & 2 \\
\hline
\end{tabular}

Figure 1 - The Portuguese Version of the Personal Health Scale.

workers presumably presented a lesser level of disability due to mental or other clinical and surgical disorders. This hypothesized difference was properly detected by the PHS$\mathrm{Pt}$, which confirms the adequacy of the instrument to reli- ably differentiate distinct populations according to a significant difference in their health statuses.

Some questions (1, 4, 5 and 9) did not reveal a significant difference between health workers and patients. Sleep 
and mood may not be impaired in outpatient volunteers without known psychiatric disorders; health workers may complain of time constraints to fully complete the requirements of their daily activities; and poor interpersonal aptitude may convey a personality trait, which may occur regardless of any physical ailment. These areas, though, may contribute to the homogeneity of the Personal Health Scale altogether.

In a series of studies conducted in New York City, the proposed cut-off score to determine the likelihood of having a mental disorder was found to be a total score of 9 or more in the validation study of the English version of PHS, whereas the proposed cut-off scores among Spanish-speaking and Chinese-speaking people in New York City were 7 and 6 respectively. Therefore, our results indicate that the cut-off point attained in the sample of Portuguese-speaking volunteers in Southern Brazil (6 or more) is within reasonable boundaries.

This study might have identifiable limitations. There is a gender disparity between patients and health professionals, in that the latter group had a smaller proportion of men. This might be related to the fact that female registered nurses and nurse assistants still outnumber their male counterparts in this region of Brazil. No gender-specific recruitment strategy was conducted in any of the research samples. Although this approach could prevent gender disproportions, it could also artificially affect voluntary en- try to the research protocol. There was a 10-year difference in the mean age of the 2 groups. Plausibly, the subsample of professionals had a lower mean age due to the retirement cap after 25 years of professional activity, a limit that obviously does not apply to patients. Additional studies encompassing different areas in the country might be necessary to generate a more representative picture of both regional and nationwide health standards among distinct samples of patients and the general population.

This study demonstrates that the original English version of the Personal Health Scale was successfully adapted to Portuguese as methodologically demonstrated herein. PHS-Pt constitutes a reliable and trustworthy research instrument for evaluating health status in Brazil, since it is appropriately designed to distinguish different groups of volunteers according to their health status. Furthermore, PHS-Pt can be conveniently used to assess health status, since it is completed both easily and quickly.

We kindly thank Prof. Carlos Pinnent, Prof. Juliana Favero Constanzi, Prof. Celso Piccoli Coelho, Dr. Katia Foresti and Dr. Gloria Johnson for their valuable assistance during distinct phases of this study. This study was partially supported by grant \# 000605-25.00/03-8 from the Secretaria de Ciência e Tecnologia do Estado do Rio Grande do Sul and by grant \# 200498/00-2 from the Conselho Nacional de Desenvolvimento Científico e Tecnológico, Brazil.

\section{RESUMO}

Zubaran C, Persch K, Tarso D, Ioppi, AE, Mezzich J. A versão em português da escala de saúde pessoal: um estudo de validação no Sul do Brasil. CLINICS. 2007;62(4):41926.

A Escala de Saúde Pessoal é um instrumento conciso para a avaliação do estado geral de saúde e bem-estar que considera os aspectos culturais e a visão pessoal do entrevistado. Ela é composta por 10 questões que avaliam diferentes dimensões de saúde obtidas a partir da literatura internacional, incluindo aspectos que variam de domínios somáticos e psicológicos até juízo critico e funcionamento social.
OBJETIVO: Nesta investigação, os resultados de um estudo conduzido no Sul do Brasil para testar e validar a versão em português da Escala de Saúde Pessoal são apresentados. MÉTODO: Este estudo analisa dados de uma amostra de 120 voluntários brasileiros (90 pacientes e 30 profissionais da saúde). Todos pacientes completaram a versão em português da Escala de Saúde Pessoal sob orientação mínima de examinadores treinados que seguiram procedimentos padronizados de instrução.

RESULTADOS: A consistência interna da PHS-Pt atingiu um índice á de Cronbach de 0.75 entre pacientes e de 0.69 entre profissionais da saúde. O coeficiente de correlação da 
validade teste-reteste indicou um escore de 0.82. Ademais, a PHS-Pt foi capaz de detectar uma significativa validade descriminante entre as duas amostra avaliada $(\mathrm{P}<.001)$.

CONCLUSÕES: A versão original em língua inglesa da Escala de Saúde Pessoal foi adaptada com sucesso para o idioma português como demonstrado metodologicamente neste estudo. A PHS-Pt constitui um instrumento de pesquisa confinável e fidedigno para avaliar o estado de saúde no Brasil, já que é apropriadamente estruturada para distinguir diferentes grupos de voluntários de acordo com seus estados de saúde.

UNITERMOS: Estado de Saúde. Estudos de validação. Questionários. Escalas. Brasil.

\section{REFERENCES}

1. von Engelhardt D. Patient vs. disease in medicine: Historical perspectives and contemporary concerns. J Nephrol. 2004;17:611-8.

2. Assessing health status and quality-of-life instruments: attributes and review criteria. Qual Life Res. 2002;11:193-205.

3. Mazze RS, Lucido D, Shamoon H. Psychological and social correlates of glycemic control. Diabetes Care. 1984;7:360-6.

4. Bebout DE, Hodgkin JE, Zorn EG, Yee AR, Sammer EA. Clinical and physiological outcomes of a university-hospital pulmonary rehabilitation program. Respir Care. 1983;28:1468-73.

5. Marks A. Health screening of the adolescent. Pediatr Nurs. 1978;4:3741.
6. Marks A. Aspects of biosocial screening and health maintenance in adolescents. Pediatr Clin North Am. 1980;27:153-61.

7. Marks A, Cohen MI. Health screening and assessment of adolescents. Pediatr Ann. 1978;7:596-604.

8. Roeske NC. Quality of life and factors affecting the response to hysterectomy. J Fam Pract. 1978;7:483-8.

9. Dolfman ML. The concept of health: an historic and analytic examination. J Sch Health. 1973;43:491-7.

10. Kaempffer AM. [Historical development of the health and disease concept]. Rev Med Chil. 1973;100(:1481-5. 
11. The WHOQOL. Quality of life assessment: international perspectives. In: Orley J KW, editor. The development of the World Health Organization quality of life assessment instrument. Springer Verlag: Heidelberg; 1994. p. 41-60.

12. Bowling A. The concept of quality of life in relation to health. Med Secoli. 1995;7:633-45.

13. Cella DF, Lloyd SR. Data collection strategies for patient-reported information. Qual Manag Health Care. 1994;2:28-35.

14. Guyatt GH. A taxonomy of health status instruments. J Rheumatol. 1995:22:1188-90.

15. Smith $P$. The role of the general health questionnaire in general practice consultations. Br J Gen Pract. 1998;48:1565-9.

16. Wolinsky FD, Wyrwich KW, Nienaber NA, Tierney WM. Generic versus disease-specific health status measures. An example using coronary artery disease and congestive heart failure patients. Eval Health Prof. 1998;21:216-43.

17. Jackowski D, Guyatt G. A guide to health measurement. Clin Orthop Relat Res. 2003:80-9.

18. Brazier JE, Harper R, Jones NM, O'Cathain A, Thomas KJ, Usherwood $\mathrm{T}$, et al. Validating the SF-36 health survey questionnaire: new outcome measure for primary care. BMJ. 1992;305:160-4.

19. Wiklund I. The Nottingham Health Profile-a measure of health-related quality of life. Scand J Prim Health Care Suppl. 1990;1:15-8.

20. Fries JF, Spitz P, Kraines RG, Holman HR. Measurement of patient outcome in arthritis. Arthritis Rheum. 1980;23:137-45.

21. Serra-Prat M, Ayllon Munoz J, Burdoy Joaquin E, Mussoll Segura J, Serra Cabot P, Papiol Rufias M, et al. [Validation of the Spanish version of the Modified Stanford Health Assessment Questionnaire (MSHAQ), an instrument to measure people's satisfaction at their ability to perform normal day-to-day activities]. Aten Primaria. 2003;32:564-70.

22. Brazier J, Jones N, Kind P. Testing the validity of the Euroqol and comparing it with the SF-36 health survey questionnaire. Qual Life Res. $1993 ; 2: 169-80$.

23. Ware J, Jr., Kosinski M, Keller SD. A 12-Item Short-Form Health Survey: construction of scales and preliminary tests of reliability and validity. Med Care. 1996;34:220-33.

24. Beaton DE, Bombardier C, Guillemin F, Ferraz MB. Guidelines for the process of cross-cultural adaptation of self-report measures. Spine. 2000;25:3186-91.

25. Bullinger M, Alonso J, Apolone G, Leplege A, Sullivan M, WoodDauphinee S, et al. Translating health status questionnaires and evaluating their quality: the IQOLA Project approach. International Quality of Life Assessment. J Clin Epidemiol. 1998;51:913-23.
26. Wiesinger GF, Nuhr M, Quittan M, Ebenbichler G, Wolfl G, FialkaMoser V. Cross-cultural adaptation of the Roland-Morris questionnaire for German-speaking patients with low back pain. Spine. 1999;24:1099103.

27. Schmidt S, Bullinger M. Current issues in cross-cultural quality of life instrument development. Arch Phys Med Rehabil. 2003;84 (4 Suppl 2):S29-34.

28. Hunt SM, Alonso J, Bucquet D, Niero M, Wiklund I, McKenna S. Crosscultural adaptation of health measures. European Group for Health Management and Quality of Life Assessment. Health Policy. 1991;19:3344.

29. Ferraz MB. Cross cultural adaptation of questionnaires: what is it and when should it be performed? J Rheumatol, 1997;24:2066-8.

30. Guillemin F, Bombardier C, Beaton D. Cross-cultural adaptation of healthrelated quality of life measures: literature review and proposed guidelines. J Clin Epidemiol. 1993;46:1417-32.

31. Hendricson WD, Russell IJ, Prihoda TJ, Jacobson JM, Rogan A, Bishop GD, et al. An approach to developing a valid Spanish language translation of a health-status questionnaire. Med Care. 1989;27:959-66.

32. Mezzich J, Ruiperez M. Presentation and Validation of the Latino Version of Personal Health Scale (PHS-La) in New York. WPA International Congress 2003.

33. Presentation and Validation of the Chinese Version of Personal Health Scale (PHS-Ch) in New York City. WPA International Congress. 2003 October 2003; Caracas.

34. Validation Study of the English Version of Personal Health Scale in New York City. WPA International Congress.; 2003 October 2003; Caracas.

35. Mezzich JE, Ruiperez MA, Perez C, Yoon G, Liu J, Mahmud S. The Spanish version of the quality of life index: presentation and validation. $\mathrm{J}$ Nerv Ment Dis. 2000;188:301-5.

36. Mari JJ, Williams P. A comparison of the validity of two psychiatric screening questionnaires (GHQ-12 and SRQ-20) in Brazil, using Relative Operating Characteristic (ROC) analysis. Psychol Med. 1985;15:651-9.

37. Arocho R, McMillan CA. Discriminant and criterion validation of the US-Spanish version of the SF-36 Health Survey in a Cuban-American population with benign prostatic hyperplasia. Med Care. 1998;36:76672.

38. Cella D, Hernandez L, Bonomi AE, Corona M, Vaquero M, Shiomoto G, et al. Spanish language translation and initial validation of the functional assessment of cancer therapy quality-of-life instrument. Med Care. 1998:36:1407-18 